\title{
Review
}

\section{Hypoxia inducible factor 1 (HIF-1) and cardioprotection}

\author{
Demet TEKIN ${ }^{2,3}$, Ali D DURSUN³ , Lei $\mathrm{XI}^{1, *}$ \\ ${ }^{1}$ Division of Cardiology, Department of Internal Medicine, Virginia Commonwealth University, Richmond, VA, USA; ${ }^{2}$ John P Hussman \\ Institute for Human Genomics, University of Miami, Miami, FL, USA; ${ }^{3}$ Department of Physiology, Ankara University, Ankara, Turkey
}

\begin{abstract}
Since its discovery in early 1990s, hypoxia inducible factor 1 (HIF-1) has been increasingly recognized for its key role in transcriptional control of more than a hundred genes that regulate a wide-spectrum of cellular functional events, including angiogenesis, vasomotor control, glucose and energy metabolism, erythropoiesis, iron homeostasis, pH regulation, cell proliferation and viability. Evidence accumulated during the past 7 years suggests a critical role for HIF-1 $\alpha$ in mediating cardioprotection. The purpose of our present article is to provide an updated overview on this important regulator of gene expression in the cellular stress-responsive and adaptive process. We have particularly emphasized the involvement of HIF-1 in the induction of cardioprotective molecules, such as inducible nitric oxide synthase (iNOS), hemeoxygenase 1 (HO-1), and erythropoietin (EPO), which in turn alleviate myocardial damages caused by harmful events such as ischemia-reperfusion injury. Despite these advances, further in-depth studies are needed to elucidate the possible coordination or interaction between HIF-1 $\alpha$ and other key transcription factors in regulating protein expression that leads to cardioprotection.
\end{abstract}

Keywords: hypoxia inducible factor; ischemia-reperfusion; myocardial infarction; preconditioning; signal transduction; cardioprotection

Acta Pharmacologica Sinica (2010) 31: 1085-1094; doi: 10.1038/aps.2010.132; published online 16 Aug 2010

\section{Introduction}

The identification of hypoxia responsive element (HRE) in the erythropoietin gene in 1991 was the first step towards the discovery of a novel transcription factor named as Hypoxia Inducible Factor 1 (HIF-1) ${ }^{[1]}$. Subsequent studies from the laboratory of Dr Gregg Semenza at the Johns Hopkins Medical Institutions revealed the protein that binds to the HRE under hypoxia as HIF-1 ${ }^{[2,3]}$.

\section{Molecular features of HIF-1}

It has been well demonstrated during the past 15 years that HIF-1 is expressed ubiquitously in almost all mammalian cells. This basic helix-loop-helix (bHLH)-Per-AHR-ARNT-Sim (PAS) transcription factor is a key element in sensing changes of cellular oxygen tension. HIF-1 is a heterodimer composed of an oxygen-sensitive a subunit and constitutively expressed $\beta$ subunit (ie arylhydrocarbon receptor nuclear translocator ARNT) ${ }^{[3]}$. More explicitly, oxygen levels can affect the protein stability, subcellular localization and transcriptional activity of the HIF a subunits (HIF-1a, HIF-2a and HIF-3a), whereas the ARNT subunit is constitutively expressed in the nucleus and its activity is not affected by hypoxia ${ }^{[4]}$. As illustrated in Figure 1, under normoxic condition, the a subunit of HIF-1 is

\footnotetext{
* To whom correspondence should be addressed.

E-mail lxi@vcu.edu

Received 2010-06-15 Accepted 2010-07-16
}

rapidly ubiquitinated and degraded proteosomally by hydroxylation of prolyl residues. This process is primarily controlled by a family of oxygen-dependent prolyl hydroxylases (PHDs; including PHD1, PHD2, and PHD3), of which the enzymatic activity is regulated by $\mathrm{O}_{2}$ availability use molecular oxygen, 2-oxo-glutarate and iron to hydroxylate these residues within the oxygen-dependent degradation domain (ODD) of HIF-1a. The product of the von Hippel-Lindau tumor suppressor gene ( $p V H L)$ then binds to these hydroxyproline residues ${ }^{[5-7]}$. Additionally, acetylation of lysine in the same domain by an acetyl transferase (ARD1) favors the interaction of HIF-1a with $\mathrm{pVHL}^{[8]}$. pVHL binding to a region of ODD of HIF a subunits initiates HIF-a proteolysis by acting as the recognition component of a ubiquitin ligase complex. Multiple ubiquitin molecules attach covalently to the targeted protein and this ubiquitin-tagged substrate is degraded by the $26 S$ proteasome $e^{[9,10]}$. In addition to proteolytic degradation, another oxygen-dependent regulatory mechanism is the inhibition of transcriptional activity of HIF-1. In normoxic condition, the factor inhibiting HIF-1 (FIH-1), $\beta$-hydroxylates the asparaginyl-803 residue of C terminal activation domain of HIF-1a, which is the interaction site for the transcriptional coactivator p300 therefore prevents the interaction of HIF-1a with coactivators ${ }^{[1]}$ (also see Figure 1).

Under hypoxic condition, HIF-1a becomes stabilized, translocates from cytoplasm to nucleus, and heterodimerizes with HIF-1 $\beta^{[3,7]}$. This hypoxia-induced nuclear translocation 


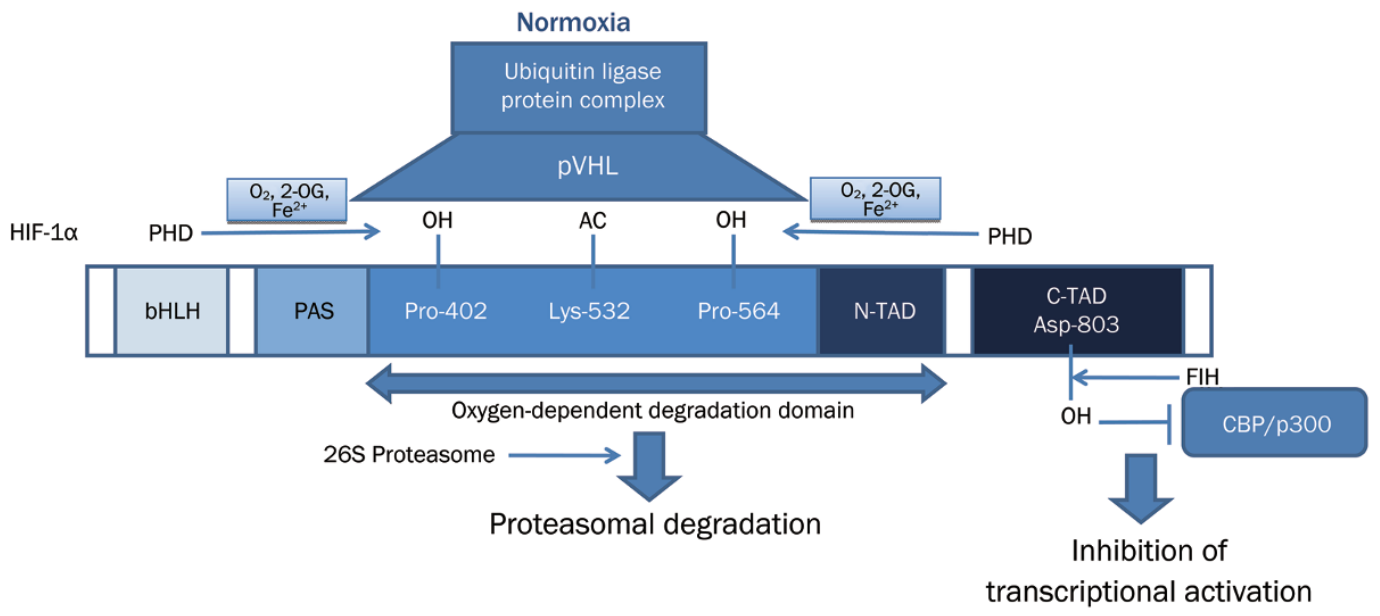

Figure 1. Cellular HIF-1 regulation under normoxic conditions. pVHL: The product of the von Hippel-Lindau tumor suppressor gene; PHD: prolyl hydroxylase; $\mathrm{OH}$ : hydroxyl; AC:acetyl; 2-OG: 2-oxoglutarate; bHLH: basic helix-loop-helix; PAS: Per/Arnt/ Sim domain; N-TAD: N-terminal transactivation domain; C-TAD: C-terminal transactivation domain; Asp: asparaginyl; Pro: Proline; Lys: Lysine; FIH: factor inhibiting HIF-1; CBP: CREB binding protein. of HIF-1a protects HIF-1a from VHL-mediated proteasomal degradation. In addition, a distinct hypoxia-dependent signal is required for stabilization of HIF-1 $\mathrm{a}^{[9]}$. The heterodimerization forms a transcriptionally active HIF complex, which in turn associates with hypoxia responsive elements (HRE) in the regulatory regions of target genes and binds to transcriptional coactivators to induce gene expression (Figure 2$)^{[3]}$. Among three HIF a isoforms, HIF-1a and HIF-2a are closely related and their transcriptional activities are both through interaction with hypoxia responsive elements of target genes ${ }^{[12]}$.

\section{HIF-1 targeted genes}

Transfer of hydrogen atoms and electrons to molecular oxygen is the final stage of oxidative phosphorylation, which is the most important mechanism of energy (ATP) production in mammalian cells. Consequently, intracellular $\mathrm{O}_{2}$ concentrations are precisely regulated in order to maintain cellular and systemic function. HIF-1 transcriptional complex plays an essential role in celular and systemic oxygen homeostasis by inducing transcription of more than a hundred hypoxia res- ponsive genes. For instance, a previous study demonstrated that more than $2 \%$ of all human genes are directly or indirectly regulated by HIF-1 in arterial endothelial cells ${ }^{[13]}$.

The genes regulated at the transcription level by HIF-1 are involved in a wide-spectrum of cellular functional events, including angiogenesis, vascular reactivity and remodeling, vasomotor control, glucose and energy metabolism, erythropoiesis, iron homeostasis, $\mathrm{pH}$ regulation, cell proliferation and viability, nucleotide metabolism, matrix metabolism, and metal transport ${ }^{[14,15]}$. Many of these functional processes are related to homeostatic responses to low oxygen tension.

Moreover, hypoxia is not the only inducer for the transcriptional activity of HIF-1 in living cells. This is because PHDs are dependent on iron as well as molecular oxygen. The displacement of iron by cobaltous ions or iron chelators inhibits the catalytic activity of the enzymes, which result in the hypoxia-independent activation of $\mathrm{HIF}^{[16-18]}$. In addition, several other non-hypoxic factors such as growth factors, interleukin 1, prostaglandin $\mathrm{E}_{2}$, thrombin, angiotensin II, serotonin, acetylcholine, thrombin, platelet-derived growth factor and

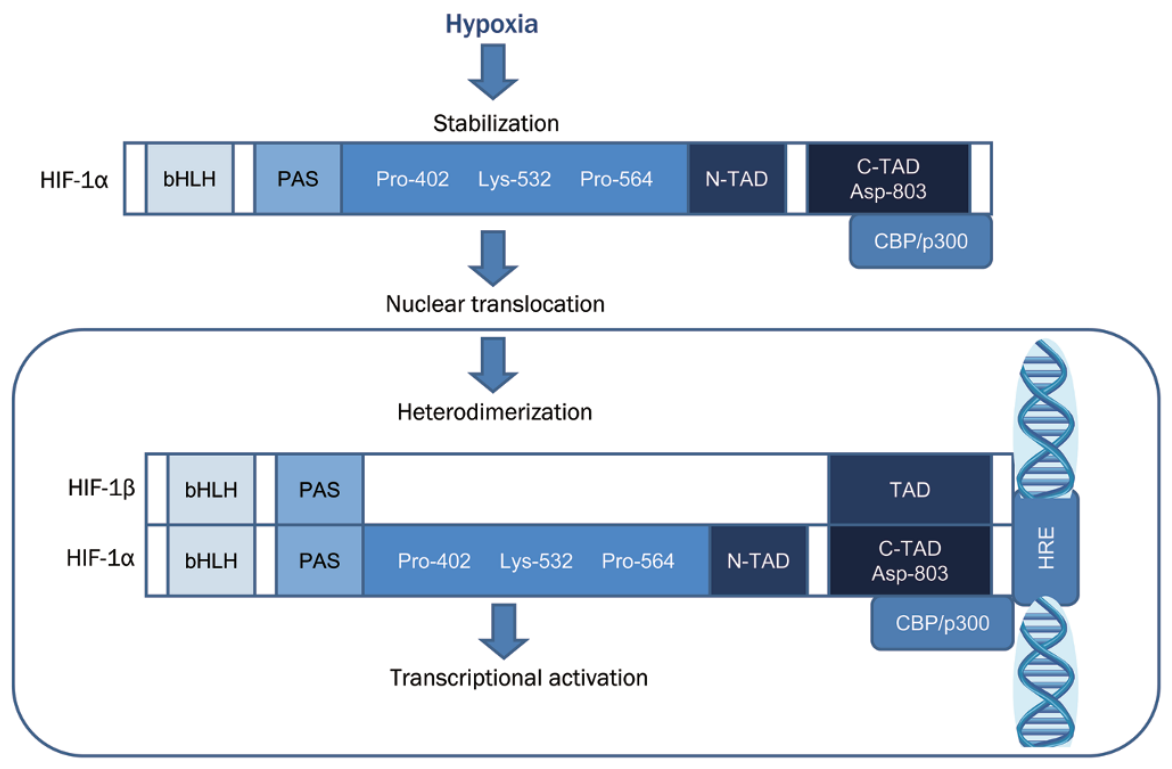

Figure 2. Cellular HIF-1 regulation under hypoxic conditions. bHLH: basic helix-loop-helix; PAS: Per/Arnt/Sim domain; Pro: Proline; Lys: Lysine; N-TAD: N-terminal transactivation domain; CTAD: C-terminal transactivation domain; Asp: asparaginyl; CBP: CREB binding protein; HRE: hypoxia responsive element. 
nitric oxide donors may also induce HIF-1 activation ${ }^{[19-21]}$.

Since the physiological function of HIF-1 in cardiorespiratory response to hypoxia was thoroughly reviewed by Dr Semenza ${ }^{[22]}$, our present review article primarily focuses on the cardioprotective roles played by HIF-1.

\section{HIF-1 and cardioprotection}

The role of HIF-1 in mediating cardioprotection was first demonstrated by Cai et al in $2003^{[23]}$. Table 1 in our present review summarizes 17 representative original investigations published since 2003, which demonstrated the crucial role for HIF-1 in various modalities of cardioprotection. We particularly emphasized a number of studies that had not been covered by the three reviews published between 2007 and 2009 on the similar topics ${ }^{[24-26]}$. The following sections individually discuss the key studies in each of the cardioprotective modalities.

\section{HIF-1 mediates cardioprotection by intermittent hypoxia}

Intermittent systemic hypoxia occurs in many common physiological and pathophysiological conditions in human life, which could be caused by environmental factors (eg high altitude) or by various cardiopulmonary disorders (eg heart failure, chronic obstructive pulmonary disease, and sleep apnea) and hematological diseases (eg anemia) $)^{[27]}$. In fact, the intermittent exposures to hypoxia are much more frequently than chronic exposure to hypoxia. Interestingly, a few wellcontrolled protocols of intermittent hypoxia can induce protective effects against myocardial infarction in rodents via a signaling mechanism that depends upon inducible nitric oxide synthase (iNOS) ${ }^{[28-30]}$. Since iNOS gene has the HRE in its promoter region and HIF-1 is essential for the hypoxic regulation of iNOS gene expression in cardiomyocytes ${ }^{[31]}$, it is logical to speculate a role for HIF-1 in intermittent hypoxia-induced cardioprotection. This concept was experimentally proved first by Cai and colleagues who demonstrated that the cardioprotective effect of intermittent hypoxia is dependent on HIF-1a gene dosage in wild-type mice, indicated by better left ventricular contractile function and significantly smaller infarct size following ischemia-reperfusion in the animals pretreated with intermittent hypoxia ${ }^{[23]}$. Moreover they found that in the heterozygous HIF-1a knockout mice, exposure to intermittent hypoxia $24 \mathrm{~h}$ before lethal ischemia had no protective effect on functional recovery or infarct size ${ }^{[23]}$. More recently, Belaidi et al showed in a rat model that intermittent hypoxia induced delayed cardioprotection against ventricular post-ischemic contractile dysfunction and myocyte necrosis was mediated by upregulation of iNOS via HIF-1 ${ }^{[28]}$. Interestingly HIF-1a is also proposed as involved in the mechanism of intermittent hypoxia induced right ventricular protection against ischemiareperfusion injury of right ventricle ${ }^{[32]}$.

Involvement of HIF-1 in ischemic preconditioning and postconditioning

Acute cardioprotection induced by either single- or multi-cycle ischemic preconditioning was completely lost in the heterozy- gous HIF-1a deficient mice. This finding proves that HIF-1a is necessary for the early window of ischemic preconditioning ${ }^{[33]}$. Previously, the same research group reported that intermittent hypoxia exposure induces HIF-1a dependent increase of erythropoietin expression in the kidney and plasma erythropoietin, which leads to the delayed window of cardioprotection in wild type but not in the partial HIF-1a deficient mice ${ }^{[23]}$. Figure 3 illustrates the suggested HIF-1a dependent cytoprotective signaling pathways in both early and late ischemic preconditioning against cardiac ischemia-reperfusion injury. Additionally, Eckle et al suggested that HIF-1a mediates ischemic preconditioning via enhanced purinergic pathways that involve the $\mathrm{A}_{2 \mathrm{~B}}$ subtype of adenosine receptors ${ }^{[34]}$.

Other investigators demonstrated that preconditioning at a remote organ such as renal ischemia-reperfusion can also induce cardioprotection ${ }^{[35]}$. Interestingly, a recent study suggested a role for HIF-1 activation in the remote renal preconditioning of rat hearts, since the authors were able to abolish the remote preconditioning by a putative activator of PHDs, alpha-ketoglutarate $(200 \mathrm{mg} / \mathrm{kg}, \mathrm{ip})^{[36]}$.

On the other hand, a few conflicting results have been published on the role of HIF-1a in ischemic preconditioning. According to the results of the study by Kawata et al, HIF-1a does not involve in VEGF upregulation in ischemic preconditioning pathway ${ }^{[37]}$. Furthermore, NF- $\mathrm{B}$ regulated genes were influenced by ischemic preconditioning but hypoxia inducible genes were not in the patients with angina, undergoing coronary artery bypass grafting ${ }^{[38]}$.

Ischemic postconditioning is a cardioprotective modality against reperfusion injury through series of brief reflow interruptions applied at the very onset of reperfusion ${ }^{[39]}$. Postconditioning can activate a complex cellular signaling cascade, in which cell membrane receptors could serve as the upstream triggers $^{[40]}$. Interestingly, few recent studies have shown that HIF-1a upregulation is associated with the postconditioningmediated cardioprotection against ischemia-reperfusion injury in normal and hypercholesterolemic animals ${ }^{[41,42]}$.

\section{Cardioprotection by pharmacological activators of HIF-1 Cobalt chloride}

Our group was the first to discover the cardioprotective effects induced by $\mathrm{CoCl}_{2}{ }^{[17]}$. We found that a single low dose of $\mathrm{CoCl}_{2}$ induced delayed cardioprotection through selective activation of HIF-1a, AP-1, and iNOS, without affecting another key transcription factor - nuclear factor kappa B in mice ${ }^{[17]}$. Our findings were conceptually confirmed by others in a translational model of myocardial ischemia-reperfusion injury following deep hypothermic circulatory arrest in neonatal piglets ${ }^{[43]}$. $\mathrm{CoCl}_{2}$ pretreatment significantly attenuated myocardial apoptosis and the cardioprotective effects were associated with enhanced cardiac expression of phosphorylated Akt and anti-apoptotic protein Bcl-2 and decreased expression of proapoptotic protein $\mathrm{Bax}^{[43]}$.

\section{Volatile anesthetics}

Volatile anesthetics are known to produce pharmacological 
Table 1. Representative publications demonstrating cardioprotective role of HIF- $1 \alpha$.

\begin{tabular}{ll}
\hline \multicolumn{1}{c}{ Cardioprotective modality } & \multicolumn{1}{c}{ Significant end-points } \\
\hline Intermittent hypoxia induced & Myocardial infarct size; cardiac func- \\
delayed PC is lost in hetero- & tion; kidney EPO mRNA expression; \\
zygous HIF-1 $\alpha$ knockout mice & Plasma EPO levels
\end{tabular}

$\mathrm{CoCl}_{2}(30 \mathrm{mg} / \mathrm{kg})$ induced activation of HIF-1 $\alpha$ induces delayed PC via an iNOS-dependent pathway

DMOG induced activation of HIF-1 $\alpha$ induces delayed PC via an HO-1-dependent anti-inflammatory mechanism

Hypoxic PC and adenovirus mediated HIF-1 $\alpha$ overexpression reduce $\mathrm{I} / \mathrm{R}$ induced cardiac cell death by late phase PC

Constitutive overexpression of HIF-1 $\alpha$ in transgenic mice results in delayed cardioprotection

Normoxic activation of HIF1 in hearts following in vivo PHD2 siRNA administration attenuates reperfusion injury via an iNOS-dependent pathway

siRNA mediated HIF-1 activation induces cardioprotection via adiponectin in diabetic hearts

Deferoxamine directed upregulation of HIF-1 $\alpha$ induces PC through improvement of cGMP signalling

Isoflurane induces early pharmacological PC mediated by HIF- $1 \alpha$ activation

Myocardial infarct size; HIF-1 $\alpha$ and AP-1 DNA binding activity $1 \alpha$ protein expressions; serum IL- 8 levels; myocardial PMN infiltration; HIF-1 activated anti-inflammatory parameters in HMEC in vitro

Mitochondrial function, cell viability and LDH levels for PC effect; VEGF, and endogenous HIF-1 $\alpha$ protein expressions

Myocardial infarct size; cardiac function; capillary density, HIF-1 $\alpha$, VEGF and iNOS expressions

Myocardial infarct size; cardiac functions; cardiac HIF-1 $\alpha$ and iNOS protein expressions

Myocardial infarct size; cardiac functions; HIF-1 binding to and transactivation of adiponectin promoter; tissue adiponectin mRNA expressions

Percentage and rate of cardiomyocyte shortenning; phosphorylation activity of cGMP

Myocardial infarct size; CK-MB levels; HIF-1 $\alpha$ protein expression and DNA binding
Mouse

Species

Rat \& mouse

Systemic intermittent hypoxic PC (5 cycles of $6 \% \mathrm{O}_{2}$ for $6^{\prime} / 21 \% \mathrm{O}_{2}$ for $6^{\prime}$ ); global l/R injury $\left(30^{\prime} / 2 \mathrm{~h}\right)$ in isolated perfused heart in a working mode; RT-PCR for EPO, EPOR, Glut-

1, iNOS, and VEGF mRNA; plasma EPO levels; apoptosis assays

DNA binding activity by EMSA; iNOS knockout; global I/R injury $\left(20^{\prime} / 30^{\prime}\right)$ in Langendorff isolated perfused heart model

Myocardial infarct size; HO-1 and HIF- Rabbit Glut-1, Glut-4, HSP70 and iNOS mRNA endothelial, cardiac and white adipose
Rat

DMOG induced HIF- $1 \alpha$ activation; inflammatuar markers in HMEC and myocardium; I/R injury $\left(30^{\prime} / 180^{\prime}\right)$ by coronary ligation in vivo

HIF-1 $\alpha$ overexpression by infection with recombinant adenoviral vectors; hypoxic PC $(3 \mathrm{~h} / 14 \mathrm{~h}$ ) and simulated I/R injury (2 h/15 h) of cardiomyocytes; mRNA expressions by QPCR

Mouse

HIF-1 $\alpha$ overexpression by transgenic mice; ischemia injury by coronary ligation in vivo; cardiac functional measurement by 2D/M-mode echocardiography; immunhistochemistry, Western blotting and Northernblotting for gene/protein expressions

Mouse HIF-1 activation via siRNA-mediated PHD2 gene silencing; iNOS knockout; I/R injury $\left(30^{\prime} / 60^{\prime}\right)$ in Langendorff isolated perfused heart model

Mouse

HIF-1 activation via siRNA-mediated PHD-2 gene silencing; HIF-1 binding to adiponectin by EMSA; Adiponectin expression by QPCR; I/R injury $\left(30^{\prime} / 60^{\prime}\right)$ in Langendorff isolated perfused heart model

Rabbit HIF-1 $\alpha$ upregulation by deferoxamine (150 $\mathrm{mg} / \mathrm{kg}$ for 2 days); cyclic GMP protein kinase activity by a protein phosphorylation assay; simulated I (15' 95\% $\left.\mathrm{N}_{2}-5 \% \mathrm{CO}_{2}\right) / \mathrm{R}\left(30^{\prime}\right)$ injury of cardiomyoctes

Rabbit

Isoflurane (1 MAC) and rapamycin (0.25 $\mathrm{mg} / \mathrm{kg}$ ) treatment; HIF-1 $\alpha$ expression by WB; $\quad$ al, $2008^{[45]}$ HIF-1 $\alpha$ DNA binding by EMSA; regional I/R injury $\left(40^{\prime} / 180^{\prime}\right)$ by coronary ligation in vivo
Raphael et

Ockaili et al, $2005^{[48]}$

Date et al, $2005^{[58]}$

Kido et al, $2005^{[62]}$

Natarajan et al, 2006 ${ }^{[53]}$

Natarajan et al, 2008 ${ }^{[55]}$

Luciano et al, 2008 $8^{[50]}$

(Continued) 


\begin{tabular}{llll}
\hline Cardioprotective modality & Significant end-points & Species & Methods
\end{tabular}

Ischemic early window of PC is lost in heterozygous HIF-1 $\alpha$ knockout mice

HIF-1 has a central role in ischemic $\mathrm{PC}$ via transcriptional activation of purinergic signaling pathways

Deferoxamine and CPX directed upregulation of HIF- $1 \alpha$ induces PC by improved contractile and calcium handling responses to inotropic agents

The upregulation of HIF- $1 \alpha$ during hypoxic preconditioning by inhibition of miR-199a
Myocardial infarct size; cardiac function; apoptosis; impaired mitochondrial ROS production, PTEN oxidation and AKT phosphorylation in heterozygous HIF-1 $\alpha$ knockout mice

Myocardial infarct size; cardiac protein Mouse expression and nuclear translocation of HIF-1 $\alpha$; PHD-1, -2, -3, and adenosine receptor transcript and protein levels; plasma troponin I levels; cardiac adenosine levels

Percentage and rate of cardiomyocyte shortenning; parameters of intracellular $\mathrm{Ca}^{2+}$ transient

miR-199a down-regulation and HIF$1 \alpha$ and Sirt 1 upregulations during hypoxia; miR-199 inhibition of HIF-1 $\alpha$ and Sirt1; mitochondrial integrity and longevity of cardiac cells

Myocardial infarct size; cardiac function; expression of HIF- $1 \alpha$ and HO-1 in the skeletal muscle; $\mathrm{HO}-1$ activity against I/R injury

Mild exercise training induces cardioprotection by few significant genes including HIF-1 $\alpha$

Mouse

Rat

Myocardial infarct size; caveolin 3, enolase 2 and HIF-1 $\alpha$ expressions

Rat
Rabbit HIF-1 $\alpha$ upregulation by deferoxamine (150 mg/kg

Mouse HIF-1 $\alpha$ and HO-1 gene delivery to skeletal muscle;

Mouse Generation of Hif-p4h-2 $2^{\mathrm{g} t \mathrm{gt}}$ mice; Q-PCR and micro-

$2 \alpha$ and by induction of genes

in glucose metabolism, cardiac function and blood pressure

Chronic post-myocardial infarction oral treatment with a novel selective PHD inhibitorGSK360A (30 mg/kg/day for 28 days) improves long-term ventricular function, remodeling, and vascularity
$\mathrm{LDH}$ release; cardiac function; coronary flow rate; Hif-p4h-2 mRNA and protein expression in several tissues; cardiac upregulation of HIF targeted genes; cardiac energy metabolite levels

Circulating levels of EPO and hemoglobin; HO-1 expression in heart and skeletal muscle; left ventricular ejection fraction and chamber dilation; lung weight; microvascular density in peri-infarct region; survival rate
Ischemic PC (I/R for $10^{\prime} / 5^{\prime}$ or 2 cycles of I/R for $\left.5^{\prime} / 5^{\prime}\right)$; global I/R injury $\left(30^{\prime} / 45^{\prime}\right)$ in Langendorff isolated perfused heart model; Immunblotting for PTEN and AKT; apoptosis assays; mitochondrial ROS production

In vivo siRNA repression of cardiac HIF-1 $1 \alpha$; tissue adenosine levels via HPLC; immunhistochemistry, transcriptional analysis and Western blotting of HIF$1 \alpha$; DMOG treatment ( $1 \mathrm{mg} / \mathrm{mouse}$, ip); ischemic in situ PC ( 4 cycles of I/R for $\left.5^{\prime} / 5^{\prime}\right)$; I/R injury $\left(60^{\prime} / 120^{\prime}\right)$ by in vivo coronary ligation for 2 days) and CPX (50 mg/kg for 2 days); measurements of intracellular $\mathrm{Ca}^{2+}$ transients; simulated I (15' 95\% $\left.\mathrm{N}_{2}-5 \% \mathrm{CO}_{2}\right) / \mathrm{R}\left(30^{\prime}\right)$ injury of cardiomyocytes

Adult and neonatal cardiomyocyte cell culture; Simulated hypoxic PC (4 cycles of $1 \mathrm{~h}$ hypoxia $1 \mathrm{~h}$ reoxygenation); Northern and Western Blotting and immunhistochemistry for the expressions of several RNAs and proteins; caspase activity and mitochondrial function Immunblotting for expression of skeletal muscle, heart, spleen and serum proteins; global I/R injury $\left(40^{\prime} / 60^{\prime}\right)$ in Langendorff isolated perfused heart model

Mild intensity training on a treadmill; gene expression profile in left ventricle by Affymetrix; real-time PCR expression of the genes; Immunohistochemistry and Western blotting; ischemia/ reperfusion injury $\left(30^{\prime} / 90^{\prime}\right)$ by coronary ligation in vivo array analysis of several genes; Western blotting for HIF- $1 \alpha$, HIF- $2 \alpha$, and HIF-P4H-2, histologic analysis of angiogenesis; $\beta$-Galactosidse activity; global I/R injury $\left(20^{\prime} / 45^{\prime}\right)$ in Langendorff isolated perfused heart model; Metabolite assays

Cai et al, $2008^{[33]}$

Eckle et al, $2008^{[34]}$

Tan et al, $2009^{[51]}$

Rane et al, 2009 ${ }^{[61]}$

Czibik et al, 2009 ${ }^{[59]}$

Giusti et al, 2009 ${ }^{[66]}$

Hyvarinen et al, 2010
Development of GSK360A - a potent inhibitor of Bao et al, PHD (PHD1>PHD2=PHD3) capable of activating the 2010 ${ }^{[52]}$ HIF-1 $\alpha$ pathway in various types of cells; Western blotting for HO-1 expression; in vivo rat model of heart failure induced by ligation of left anterior descending coronary artery; histologic analysis of angiogenesis

Abbreviations: EPO: Erythropoietin; EPOR: Erythropoietin receptor; Glut-1: Glucose transporter-1; iNOS: Inducible nitric oxide synthase; AP-1: Activating protein-1; DMOG: Dimethyloxalylglycine; HO-1: Hemoxygenase-1; HMEC: human microvascular endothelial cel line; I/R: Ischemia/Reperfusion; VEGF: Vascular endothelial growth factor; PC: Preconditioning; EMSA: Electrophoretic mobility shift assay; QPCR: Quantitative polymerase chain reaction; CPX: Ciclopirox olamine; MAC: Minimal alveolar concentration; CK-MB: Creatinin kinase-MB; WB: Western blotting; PHD: Prolyl-hydroxylase; PTEN: Phosphatase and tensin homologue; AKT: Protein kinase B; MicroRNA-199a: MiR-199a; Sirt1: Sirtuin1; HIF-P4H-2: HIF prolyl 4-hydroxylase-2. 


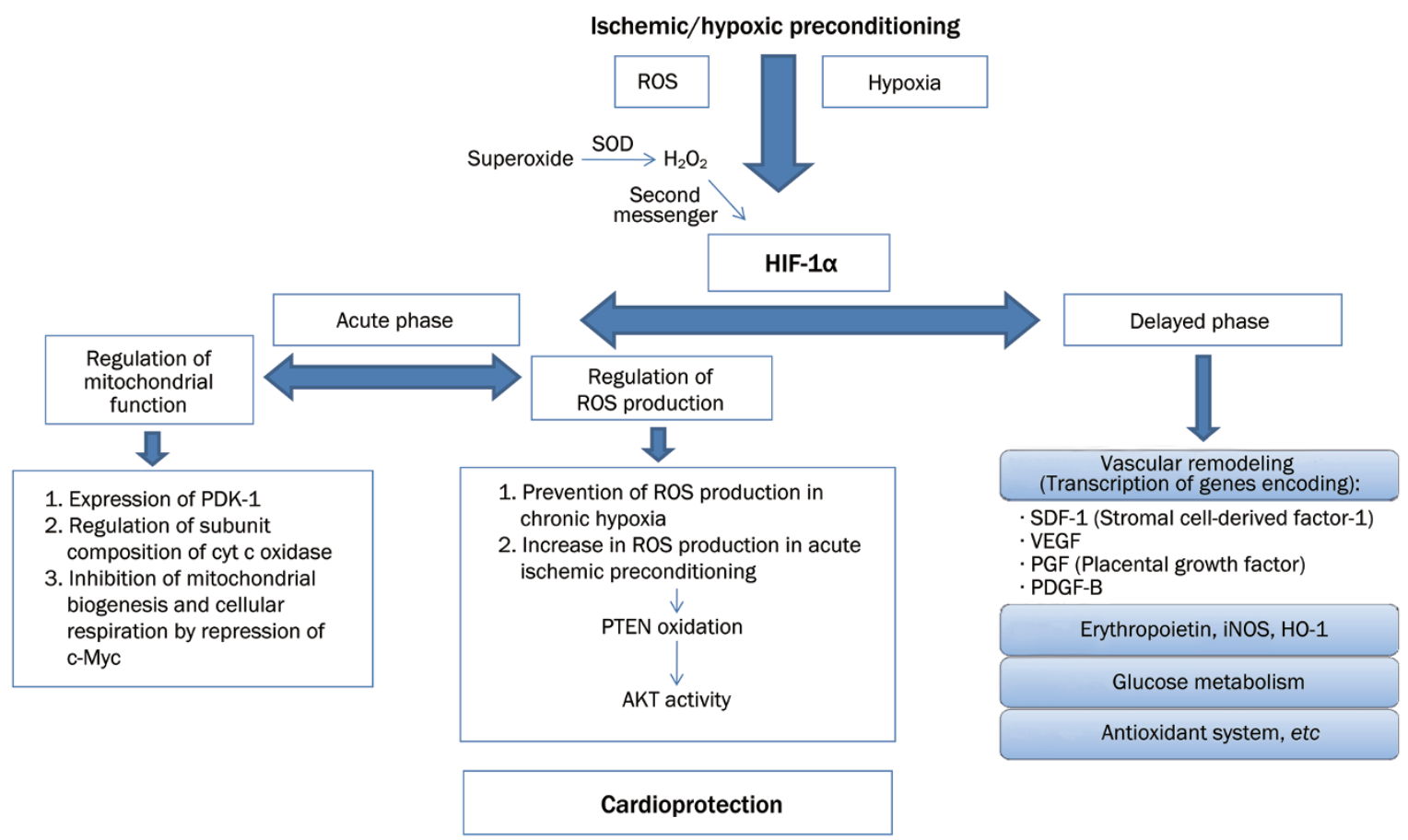

Figure 3. Proposed mechanisms of the HIF-1 $\alpha$ mediated cardioprotection by ischemic/hypoxic preconditioning. ROS: Reactive oxygen species, PDK-1: Pyruvate dehydrogenase kinase 1; PTEN: phosphatase and tensin homolog; AKT: serine/threonine kinase; iNOS: inducible nitric oxide synthase; HO-1: hemeoxygenase 1.

preconditioning effects against myocardial I/R injury. HIF-1a has been shown to play a role in the anesthetic-induced cardioprotection together with other up- or down-stream signaling proteins such as ERK1/2 and $\mathrm{VEGF}^{[44]}, \mathrm{mTOR}^{[45]}$, and $\mathrm{CREB}^{[46]}$. A more comprehensive review on this particular topic can be found in a recent work by Hieber et al ${ }^{[25]}$.

\section{Prolyl hydroxylase inhibitors}

Another therapeutic method is increasing endogenous HIF-1 level or activity by blocking HIF-1 inhibitors during normoxia or by increasing the HIF-1 stabilizing agents, which is partially discussed above under pharmacological preconditioning. Inhibition of HIF hydroxylases by 2-oxoglutarate analogs stabilizes HIF and thus hypoxia responsive genes are activated ${ }^{[47]}$. Inhibition of EGLN1/PHD prolyl hydroxylase led to tissue preservation in the rats undergoing myocardial infarction. Furthermore, HIF-1 activation through PHD inhibition by dimethyloxalylglycine (DMOG) before I/ R attenuates tissue injury in rabbit hearts, which was associated with robust expression of heme oxygenase- 1 (HO- 1$)^{[48]}$. HO-1 catalyzes the rate-limiting step of heme oxidation to biliverdin, carbon monoxide, and free ferrous iron ${ }^{[49]}$. Stabilization of HIF members by certain proteins or HIF-1 activation by PHD inhibitor DMOG $^{[48]}$ attenuates myocardial ischemia-reperfusion injury. Cardioprotection by iron chelator - deferoxamine is also associated with inhibition of $\mathrm{PHDs}^{[50]}$. These investigators also showed that upregulation of HIF-1alpha was upregulated with deferoxamine (150 mg/ kg/day for 2 days), which led to better reserved contractile functional and calcium transient in the cardiomyocytes exposed to simulated ischemia-reoxygenation in response to positive inotropic agents ${ }^{[51]}$. Most recently, chronic post-myocardial infarction treatment with a novel orally active potent PHD inhibitor - GSK360A (30 mg/ $\mathrm{kg} /$ day for 28 days, po) led to a long-term improvement in left ventricular contractile function, remodeling, and vascularity in a rat model of ischemia-induced heart failure ${ }^{[52]}$. These protective effects were associated with a significant increase of the HIF-1a regulated cardioprotective molecules such as HO-1 and $\mathrm{EPO}^{[52]}$.

\section{Cardioprotecton via activation of HIF-1 with molecular biology approaches}

Small interfering RNA (siRNA) to knockdown PHD2

It has been shown by the investigators from our institution that gene silencing of prolyl 4-hydroxylase-2 (PHD2) activates HIF-1 and protects the heart from I/R insult ${ }^{[53-55]}$. Even HIF-1 regulates cardiac metabolism in multiple ways, according to the latter research group, ischemia-reperfusion injury-induced substantial inflammatory responses that are characterized by the transcription of proinflammatory chemokines were downregulated by HIF-1 activation. Thereby the myocardial injury was reduced $^{[54]}$. More recent results from the same group showed that inhibition of PHD2 induces protective endoplasmic reticulum stress proteins and attenuates post-ischemic myocardial damage by decreasing the pro-apoptotic components of unfolded protein respons $\mathrm{e}^{[56]}$. 


\section{Gene therapies for HIF-1 overexpression or stabilization}

The knowledge on molecular mechanisms of ischemia/reperfusion injury and cardioprotection has been growing abundantly in last two decades. Clinical translation of this information to relevant preventive and therapeutic approaches is the main focus. One strategy is to give extra HIF-1 to the myocardium in certain ways. Since HIF-1a has been known to play a role in the mechanisms of several preconditioning stimuli, HIF-1a itself was used as a preconditioner before lethal ischemic attack was applied to the myocardium in many studies. For example in a previous study, a gene therapy vector, including the N-terminal DNA-binding and dimerization domain of HIF-1a fused to the strong transactivation domain of the herpes virus VP16, was developed. This naked DNA vector was given to the rat heart and myocardial responses to ischemia/reperfusion injury were improved ${ }^{[57]}$. In a cell culture environment, it was demonstrated that infection of neonatal cardiomyocytes with Ad2/HIF-1a/VP16 and Ad2/ HIF-1a/NF-kB both reduced simulated ischemia-reperfusion injury in a dose dependent manner by inducing multiple protective genes such as iNOS and VEGF ${ }^{[58]}$. Czibik et al. tried to give DNAs encoding for HIF-1a and its downstream molecule HO-1 to the skeletal muscle instead of myocardium. This remote gene delivery afforded cardioprotective effects. The downstream targets of HO-1, an antioxidant bilirubin and $\mathrm{CO}$ were suggested to be responsible from this protection ${ }^{[59]}$. Similarly, the mouse hearts infected with adenovirus encoding angiogenic Masterswitch protein PR 39 were resistant to I/R injury through prevention of HIF-1a breakdown ${ }^{[60]}$.

\section{Regulation of HIF-1 $\alpha$ by microRNAs}

MicroRNAs regulate gene expression at posttranscriptional level and may involve in major processes of cardiac physiology and pathology. A recent study reported that microRNA 199a is downregulated in cardiomyocytes in response to hypoxia and this reduction is required for the rapid upregulation of HIF-1a ${ }^{[61]}$. Replenishing microRNA 199a during hypoxia inhibits HIF-1a expression and its stabilization of p53, consequently reduces apoptosis. Conversely, knockdown of miR-199a during normoxia results in upregulation of HIF-1a and Sirtuin 1 (Sirt1) and reproduces hypoxia preconditioning. Sirt1 is also a direct target of miR-199a and is responsible for downregulating PHD2 and in turn stabilizing HIF-1a. These investigators proposed that microRNA 199a is a master regulator of hypoxia-triggered preconditioning signaling pathway against hypoxic damage in cardiomyocytes ${ }^{[61]}$.

\section{Cardioprotection in transgenic mice with upregulated or stabilized HIF-1 $\alpha$}

Kido et al demonstrated that constitutive overexpression of HIF-1a in the murine heart reduced infarct size and improved cardiac contractile function 4 weeks after myocardial infarction produced by coronary ligation. These protective effects were associated with increased capillary density as well as VEGF and iNOS expression in peri-infarct and infarct regions as compared to control animals. The authors suggested that supranormal amounts of this peptide protect against extension of infarction and improve border zone survival in myocardial infarction $^{[62]}$.

Most recently, another laboratory generated a viable PHD2 hypomorph mouse line that expresses decreased amounts of wild-type PHD2 mRNA (8\% in the heart) who have no polycythemia and show no signs of the dilated cardiomyopathy or hyperactive angiogenesis observed in mice with broad spectrum conditional PHD2 inactivation ${ }^{[63]}$. Interestingly, after ischemia-reperfusion these PHD2-inactivated hearts had significantly better functional recovery and coronary flow rate, and lower level of lactate dehydrogenase leakage as compared with the wild type controls. Furthermore, these anti-ischemia protective effects were accompanied by enhanced glycolysis and improved cellular energy state ${ }^{[64]}$.

\section{HIF-1 and excercise-induced cardioprotection}

There has been a general consensus that exercise-induced cardioprotection against myocardial ischemia-reperfusion injury is through a series of adaptative changes, which may include new vessel formation in coronary arteries, increased cardiomyocyte oxygen utilization with changes in mitochondrial metabolisms, induction of heat shock proteins, opening of sarcolemmal and mitochondrial ATP sensitive potassium channels and enhancement of cardiac nitric oxide production and antioxidant capacity ${ }^{[65]}$. The possible involvement of HIF-1 in exercise-induced cardioprotection was recently demonstrated by Giusti et al ${ }^{[66]}$. In a rat model of chronic exercise-induced cardioprotection, these researchers found that HIF-1a was among the genes that were significantly upregulated in the left ventricular tissues 48 hours after the last training session of the 10 -week mild intensity aerobic exercise protocol. However, the causative relationship between the increased gene expression of HIF-1a and anti-ischemic cardioprotection remains to be further validated.

\section{Angiogenesis and other factors in anti-ischemic cardioprotection mediated by HIF-1}

The substrate preference of ischemic heart shifts from fatty acid to glucose utilization. The role of HIF-1a is important in the early phase of stress response where a transition from aerobic to anaerobic metabolism occurs. HIF-1a controls the factors in glucose metabolism which allows cells to shift from aerobic metabolism to anaerobic glycolysis. HIF-1a also affects mitochondrial metabolism by inducing pyruvate dehydrogenase kinase, which prevents entry of pyruvate into mitochondria, thus reduces mitochondrial respiration, and by altering composition of the cytochrome oxidase complex ${ }^{[24]}$. In addition, a previous study suggested that the adenovirus mediated expression of constitutively stable, hybrid HIF-1a protects cultured neonatal cardiomyocytes against simulated ischemia-reperfusion injury by inducing multiple protective genes $^{[58]}$. Furthermore, the levels of HIF-1a and VEGF increase in the myocardium when patients develop acute coronary artery occlusion $^{[67]}$. The increased VEGF expression by HIF-1a could induce coronary angiogenesis in myocardium, which in 
turn provides an enhanced capacity for coronary blood flow and oxygen supply to cardiac muscle during myocardial ischemic/hypoxic events ${ }^{[68,69]}$.

\section{Detrimental role of HIF-1 activation in myocardium}

Finally, despite the above-mentioned overwhelming evidence supporting the cardioprotective roles of HIF-1a, several investigators also suggested that HIF-1 activation is a detrimental factor underlying myocardial injuries. For example, Tang et al demonstrated that during ischemia-reperfusion, polyol pathway activity increases the level of transferrin receptor by inducing HIF-1a, leading to increased cellular uptake of transferrin and iron and exacerbates oxidative tissue damage by lipid peroxidation ${ }^{[70]}$. Other studies also showed that HIF-1a and VEGF mRNA and protein expression were upregulated in rat models of pressure- or volume-overload heart failure. Treatment with carvedilol, a blocker of $\beta$ adrenergic receptors was associated with a reversal of abnormal regulation of HIF-1 $a$ and VEGF in the failing ventricular myocardium ${ }^{[71,72]}$. Sustained activation of HIF-1 in the transgenic mice lacking PHD2 exhibit premature mortality associated with marked venous congestion and dilated cardiomyopathy ${ }^{[63]}$. The authors proposed that the chronic HIF-1 activation induced cardiomyopathy could be resulted from the blood hyperviscosity and volume overload, although a direct detrimental effect on cardiac myocytes cannot be excluded. Nevertheless, these opposing views on HIF-1 remain to be further evaluated in various specific pathological settings.

\section{Summary}

The present article provides an updated overview on the critical involvement of HIF-1a in regulation of the stress-responsive gene expression as well as in mediating anti-ischemic cardioprotection induced by a number of physiological, pharmacological, and molecular approaches. These include intermittent hypoxia, ischemic or pharmacological preconditioning and postconditioning, HIF-1a gene therapy, PHD2-targeted siRNA, microRNA, and transgenic mouse models, which lead to signal transduction and adaptive changes that in turn alleviate myocardial damages caused by harmful events such as ischemia-reperfusion injury. Despite these new advances, further in-depth studies are needed to elucidate the possible coordination or interaction between HIF-1a and other key transcription factors (such as NF-kB, AP-1, and GATA-4) in regulating expression of the proteins that lead to cardioprotection.

\section{References}

1 Semenza GL, Nejfelt MK, Chi SM, Antonarakis SE. Hypoxia-inducible nuclear factors bind to an enhancer element located $3^{\prime}$ to the human erythropoietin gene. Proc Natl Acad Sci USA 1991; 88: 5680-4.

2 Wang GL, Jiang BH, Rue EA, Semenza GL. Hypoxia-inducible factor 1 is a basic-helix-loop-helix-PAS heterodimer regulated by cellular $\mathrm{O}_{2}$ tension. Proc Natl Acad Sci USA 1995; 92: 5510-4.

3 Wang GL, Semenza GL. Purification and characterization of hypoxiainducible factor 1. J Biol Chem 1995; 270: 1230-7.
4 Li H, Ko HP, Whitlock JP. Induction of phosphoglycerate kinase 1 gene expression by hypoxia. Roles of Arnt and HIF1alpha. J Biol Chem 1996; 271: 21262-7.

5 Jaakkola P, Mole DR, Tian YM, Wilson MI, Gielbert J, Gaskell SJ, et al. Targeting of HIF-alpha to the von Hippel-Lindau ubiquitylation complex by $\mathrm{O}_{2}$-regulated prolyl hydroxylation. Science 2001; 292: 468-72.

6 Ivan M, Kondo K, Yang H, Kim W, Valiando J, Ohh M, et al. HIFalpha targeted for VHL-mediated destruction by proline hydroxylation: implications for $\mathrm{O}_{2}$ sensing. Science 2001; 292: 464-8.

7 Salceda S, Caro J. Hypoxia-inducible factor 1alpha (HIF-1alpha) protein is rapidly degraded by the ubiquitin-proteasome system under normoxic conditions. Its stabilization by hypoxia depends on redoxinduced changes. J Biol Chem 1997; 272: 22642-7.

8 Jeong JW, Bae MK, Ahn MY, Kim SH, Sohn TK, Bae MH, et al. Regulation and destabilization of HIF-1alpha by ARD1-mediated acetylation. Cell 2002; 111: 709-20.

9 Tanimoto K, Makino Y, Pereira T, Poellinger L. Mechanism of regulation of the hypoxia-inducible factor-1 alpha by the von Hippel-Lindau tumor suppressor protein. EMBO J 2000; 19: 4298-309.

10 Cockman ME, Masson N, Mole DR, Jaakkola P, Chang GW, Clifford SC, et al. Hypoxia inducible factor-alpha binding and ubiquitylation by the von Hippel-Lindau tumor suppressor protein. J Biol Chem 2000; 275: 25733-41.

11 Lando D, Peet DJ, Gorman JJ, Whelan DA, Whitelaw ML, Bruick RK. FIH-1 is an asparaginyl hydroxylase enzyme that regulates the transcriptional activity of hypoxia-inducible factor. Genes Dev 2002; 16: 1466-71.

12 Ema M, Taya S, Yokotani N, Sogawa K, Matsuda Y, Fujii-Kuriyama Y. A novel bHLH-PAS factor with close sequence similarity to hypoxiainducible factor 1alpha regulates the VEGF expression and is potentially involved in lung and vascular development. Proc Natl Acad Sci USA 1997; 94: 4273-8.

13 Manalo DJ, Rowan A, Lavoie T, Natarajan L, Kelly BD, Ye SQ, et al. Transcriptional regulation of vascular endothelial cell responses to hypoxia by HIF-1. Blood 2005; 105: 659-69.

14 Maxwell PH, Ratcliffe PJ. Oxygen sensors and angiogenesis. Semin Cell Dev Biol 2002; 13: 29-37.

15 Semenza GL, Shimoda LA, Prabhakar NR. Regulation of gene expression by HIF-1. Novartis Found Symp 2006; 272: 2-8.

16 Gleadle JM, Ebert BL, Firth JD, Ratcliffe PJ. Regulation of angiogenic growth factor expression by hypoxia, transition metals, and chelating agents. Am J Physiol 1995; 268: C1362-C1368.

17 Xi L, Taher M, Yin C, Salloum F, Kukreja RC. Cobalt chloride induces delayed cardiac preconditioning in mice through selective activation of HIF-1alpha and AP-1 and iNOS signaling. Am J Physiol Heart Circ Physiol 2004; 287: H2369-75.

18 Yuan Y, Hilliard G, Ferguson T, Millhorn DE. Cobalt inhibits the interaction between hypoxia-inducible factor-alpha and von Hippel-Lindau protein by direct binding to hypoxia-inducible factor-alpha. J Biol Chem 2003; 278: 15911-6.

19 Tsukiyama F, Nakai Y, Yoshida M, Tokuhara T, Hirota K, Sakai A, et al. Gallate, the component of HIF-inducing catechins, inhibits HIF prolyl hydroxylase. Biochem Biophys Res Commun 2006; 351: 234-9.

20 Page EL, Robitaille GA, Pouyssegur J, Richard DE. Induction of hypoxia-inducible factor-1alpha by transcriptional and translational mechanisms. J Biol Chem 2002; 277: 48403-9.

21 Gorlach A, Diebold I, Schini-Kerth VB, Berchner-Pfannschmidt U, Roth U, Brandes RP, et al. Thrombin activates the hypoxia-inducible factor-1 signaling pathway in vascular smooth muscle cells: Role of the p22(phox)-containing NADPH oxidase. Circ Res 2001; 89: 47-54. 22 Semenza GL. 02-regulated gene expression: transcriptional control 
of cardiorespiratory physiology by HIF-1. J Appl Physiol 2004; 96: 1173-7.

23 Cai Z, Manalo DJ, Wei G, Rodriguez ER, Fox-Talbot K, Lu H, et al. Hearts from rodents exposed to intermittent hypoxia or erythropoietin are protected against ischemia-reperfusion injury. Circulation 2003; 108: $79-85$.

24 Shohet RV, Garcia JA. Keeping the engine primed: HIF factors as key regulators of cardiac metabolism and angiogenesis during ischemia. J Mol Med 2007; 85: 1309-15.

25 Hieber S, Huhn R, Hollmann MW, Weber NC, Preckel B. Hypoxiainducible factor 1 and related gene products in anaesthetic-induced preconditioning. Eur J Anaesthesiol 2009; 26: 201-6.

26 Loor G, Schumacker PT. Role of hypoxia-inducible factor in cell survival during myocardial ischemia-reperfusion. Cell Death Differ 2008; 15: 686-90.

27 Xi L, Serebrovskaya TV. Intermittent hypoxia: from molecular mechanisms to clinical applications. New York: Nova Science Publishers; 2009. p 1-615.

28 Belaidi E, Beguin PC, Levy P, Ribuot C, Godin-Ribuot D. Prevention of HIF-1 activation and iNOS gene targeting by low-dose cadmium results in loss of myocardial hypoxic preconditioning in the rat. Am J Physiol Heart Circ Physiol 2008; 294: H901-H908.

29 Ding HL, Zhu HF, Dong JW, Zhu WZ, Yang WW, Yang HT, et al. Inducible nitric oxide synthase contributes to intermittent hypoxia against ischemia/reperfusion injury. Acta Pharmacol Sin 2005; 26 : 315-22.

30 Xi L, Tekin D, Gursoy E, Salloum F, Levasseur JE, Kukreja RC. Evidence that NOS2 acts as a trigger and mediator of late preconditioning induced by acute systemic hypoxia. Am J Physiol Heart Circ Physiol 2002; 283: H5-12.

31 Jung F, Palmer LA, Zhou N, Johns RA. Hypoxic regulation of inducible nitric oxide synthase via hypoxia inducible factor-1 in cardiac myocytes. Circ Res 2000; 86: 319-25.

32 Wasserfuhr D, Cetin SM, Yang J, Freitag P, Frede S, Jakob H, et al. Protection of the right ventricle from ischemia and reperfusion by preceding hypoxia. Naunyn Schmiedebergs Arch Pharmacol 2008; 378: 27-32.

33 Cai Z, Zhong H, Bosch-Marce M, Fox-Talbot K, Wang L, Wei C, et al. Complete loss of ischaemic preconditioning-induced cardioprotection in mice with partial deficiency of HIF-1 alpha. Cardiovasc Res 2008; 77: 463-70.

34 Eckle T, Kohler D, Lehmann R, El Kasmi K, Eltzschig HK. Hypoxiainducible factor-1 is central to cardioprotection: a new paradigm for ischemic preconditioning. Circulation 2008; 118: 166-75.

35 Takaoka A, Nakae I, Mitsunami K, Yabe T, Morikawa S, Inubushi T, et al. Renal ischemia/reperfusion remotely improves myocardial energy metabolism during myocardial ischemia via adenosine receptors in rabbits: effects of "remote preconditioning". J Am Coll Cardiol 1999; 33: 556-64.

36 Kant R, Diwan V, Jaggi AS, Singh N, Singh D. Remote renal preconditioning-induced cardioprotection: a key role of hypoxia inducible factorprolyl 4-hydroxylases. Mol Cell Biochem 2008; 312: 25-31.

37 Kawata H, Yoshida K, Kawamoto A, Kurioka H, Takase E, Sasaki Y, et al. Ischemic preconditioning upregulates vascular endothelial growth factor mRNA expression and neovascularization via nuclear translocation of protein kinase $\mathrm{C}$ epsilon in the rat ischemic myocardium. Circ Res 2001; 88: 696-704.

38 Czibik G, Wu Z, Berne GP, Tarkka M, Vaage J, Laurikka J, et al. Human adaptation to ischemia by preconditioning or unstable angina: involvement of nuclear factor kappa B, but not hypoxia-inducible factor 1 alpha in the heart. Eur J Cardiothorac Surg 2008; 34: 976-84.
39 Zhao ZQ, Corvera JS, Halkos ME, Kerendi F, Wang NP, Guyton RA, et al. Inhibition of myocardial injury by ischemic postconditioning during reperfusion: comparison with ischemic preconditioning. Am J Physiol Heart Circ Physiol 2003; 285: H579-88.

40 Xi L, Das A, Zhao ZQ, Merino VF, Bader M, Kukreja RC. Loss of myocardial ischemic postconditioning in adenosine $A 1$ and bradykinin B2 receptors gene knockout mice. Circulation 2008; 118: S32-7.

41 Zhao HX, Wang XL, Wang YH, Wu Y, Li XY, Lv XP, et al. Attenuation of myocardial injury by postconditioning: role of hypoxia inducible factor1alpha. Basic Res Cardiol 2010;105: 109-18.

42 Zhao H, Wang Y, Wu Y, Li X, Yang G, Ma X, et al. Hyperlipidemia does not prevent the cardioprotection by postconditioning against myocardial ischemia/reperfusion injury and the involvement of hypoxia inducible factor-1alpha upregulation. Acta Biochim Biophys Sin 2009; 41: 745-53.

43 Kerendi F, Kirshbom PM, Halkos ME, Wang NP, Kin H, Jiang R, et al. Thoracic Surgery Directors Association Award. Cobalt chloride pretreatment attenuates myocardial apoptosis after hypothermic circulatory arrest. Ann Thorac Surg 2006; 81: 2055-62.

44 Wang C, Weihrauch D, Schwabe DA, Bienengraeber M, Warltier $\mathrm{DC}$, Kersten JR, et al. Extracellular signal-regulated kinases trigger isoflurane preconditioning concomitant with upregulation of hypoxiainducible factor-1alpha and vascular endothelial growth factor expression in rats. Anesth Analg 2006; 103: 281-8.

45 Raphael J, Zuo Z, Abedat S, Beeri R, Gozal Y. Isoflurane preconditioning decreases myocardial infarction in rabbits via up-regulation of hypoxia inducible factor 1 that is mediated by mammalian target of rapamycin. Anesthesiology 2008; 108: 415-25.

46 Feng J, Lucchinetti E, Fischer G, Zhu M, Zaugg K, Schaub MC, et al. Cardiac remodelling hinders activation of cyclooxygenase-2, diminishing protection by delayed pharmacological preconditioning: role of HIF1 alpha and CREB. Cardiovasc Res 2008;78: 98-107.

47 Ivan M, Haberberger T, Gervasi DC, Michelson KS, Gunzler V, Kondo $\mathrm{K}$, et al. Biochemical purification and pharmacological inhibition of $\mathrm{a}$ mammalian prolyl hydroxylase acting on hypoxia-inducible factor. Proc Natl Acad Sci USA 2002; 99: 13459-64.

48 Ockaili R, Natarajan R, Salloum F, Fisher BJ, Jones D, Fowler AA III, et al. HIF-1 activation attenuates postischemic myocardial injury: role for heme oxygenase-1 in modulating microvascular chemokine generation. Am J Physiol Heart Circ Physiol 2005; 289: H542-8.

49 Ryter SW, Otterbein LE, Morse D, Choi AM. Heme oxygenase/carbon monoxide signaling pathways: regulation and functional significance. Mol Cell Biochem 2002; 234-235: 249-63.

50 Luciano JA, Tan T, Zhang Q, Huang E, Scholz P, Weiss HR. Hypoxia inducible factor- 1 improves the actions of nitric oxide and natriuretic peptides after simulated ischemia-reperfusion. Cell Physiol Biochem 2008; 21: 421-8.

51 Tan T, Luciano JA, Scholz PM, Weiss HR. Hypoxia inducible factor-1 improves the actions of positive inotropic agents in stunned cardiac myocytes. Clin Exp Pharmacol Physiol 2009; 36: 904-11.

52 Bao W, Qin P, Needle S, Erickson-Miller CL, Duffy KJ, Ariazi JL, et al. Chronic inhibition of hypoxia-inducible factor (hif) prolyl 4-hydroxylase improves ventricular performance, remodeling and vascularity following myocardial infarction in the rat. J Cardiovasc Pharmacol 2010. doi: 10.1097/FJC.0b013e3181e2bfef

53 Natarajan R, Salloum FN, Fisher BJ, Kukreja RC, Fowler AA III. Hypoxia inducible factor-1 activation by prolyl 4-hydroxylase-2 gene silencing attenuates myocardial ischemia reperfusion injury. Circ Res 2006; 98: $133-40$.

54 Natarajan R, Salloum FN, Fisher BJ, Ownby ED, Kukreja RC, Fowler AA III. Activation of hypoxia-inducible factor-1 via prolyl-4 hydoxylase-2 
gene silencing attenuates acute inflammatory responses in postischemic myocardium. Am J Physiol Heart Circ Physiol 2007; 293: H1571-80.

55 Natarajan R, Salloum FN, Fisher BJ, Kukreja RC, Fowler AA III. Hypoxia inducible factor-1 upregulates adiponectin in diabetic mouse hearts and attenuates post-ischemic injury. J Cardiovasc Pharmacol 2008; 51: 178-87.

56 Natarajan R, Salloum FN, Fisher BJ, Smithson L, Almenara J, Fowler AA III. Prolyl hydroxylase inhibition attenuates post-ischemic cardiac injury via induction of endoplasmic reticulum stress genes. Vascul Pharmacol 2009; 51: 110-8.

57 Shyu KG, Wang MT, Wang BW, Chang CC, Leu JG, Kuan P, et al. Intramyocardial injection of naked DNA encoding HIF-1alpha/VP16 hybrid to enhance angiogenesis in an acute myocardial infarction model in the rat. Cardiovasc Res. 2002; 54: 576-83.

58 Date T, Mochizuki S, Belanger AJ, Yamakawa M, Luo Z, Vincent KA, et al. Expression of constitutively stable hybrid hypoxia-inducible factor-1alpha protects cultured rat cardiomyocytes against simulated ischemia-reperfusion injury. Am J Physiol Cell Physiol 2005; 288: c314-20.

59 Czibik G, Martinov V, Ruusalepp A, Sagave J, Skare O, Valen G. In vivo remote delivery of DNA encoding for hypoxia-inducible factor 1 alpha reduces myocardial infarct size. Clin TransI Sci 2009; 2: 33-40.

60 Muinck ED, Nagy N, Tirziu D, Murakami M, Gurusamy N, Goswami SK, et al. Protection against myocardial ischemia-reperfusion injury by the angiogenic Masterswitch protein PR 39 gene therapy: the roles of HIF1alpha stabilization and FGFR1 signaling. Antioxid Redox Signal 2007; 9: 437-45.

61 Rane S, He M, Sayed D, Vashistha H, Malhotra A, Sadoshima J, et al. Downregulation of miR-199a derepresses hypoxia-inducible factor1alpha and Sirtuin 1 and recapitulates hypoxia preconditioning in cardiac myocytes. Circ Res 2009; 104: 879-86.

62 Kido M, Du L, Sullivan CC, Li X, Deutsch R, Jamieson SW, et al. Hypoxia-inducible factor 1-alpha reduces infarction and attenuates progression of cardiac dysfunction after myocardial infarction in the mouse. J Am Coll Cardiol 2005; 46: 2116-24.
63 Minamishima YA, Moslehi J, Bardeesy N, Cullen D, Bronson RT, Kaelin WG Jr. Somatic inactivation of the PHD2 prolyl hydroxylase causes polycythemia and congestive heart failure. Blood 2008; 111: 323644.

64 Hyvarinen J, Hassinen IE, Sormunen R, Maki JM, Kivirikko KI, Koivunen $\mathrm{P}$, et al. Hearts of hypoxia-inducible factor prolyl 4-hydroxylase-2 hypomorphic mice show protection against acute ischemiareperfusion injury. J Biol Chem 2010; 285: 13646-57.

65 Kavazis AN. Exercise preconditioning of the myocardium. Sports Med 2009; 39: 923-35.

66 Giusti B, Marini M, Rossi L, Lapini I, Magi A, Capalbo A, et al. Gene expression profile of rat left ventricles reveals persisting changes following chronic mild exercise protocol: implications for cardioprotection. BMC Genomics. 2009; 10: 342.

67 Lee SH, Wolf PL, Escudero R, Deutsch R, Jamieson SW, Thistlethwaite PA. Early expression of angiogenesis factors in acute myocardial ischemia and infarction. N Engl J Med 2000; 342: 626-33.

68 Martin C, Yu AY, Jiang BH, Davis L, Kimberly D, Hohimer AR, et al. Cardiac hypertrophy in chronically anemic fetal sheep: Increased vascularization is associated with increased myocardial expression of vascular endothelial growth factor and hypoxia-inducible factor 1 . Am J Obstet Gynecol 1998; 178: 527-34.

69 Semenza GL. Regulation of tissue perfusion in mammals by hypoxiainducible factor 1. Exp Physiol 2007; 92: 988-91.

70 Tang WH, Wu S, Wong TM, Chung SK, Chung SS. Polyol pathway mediates iron-induced oxidative injury in ischemic-reperfused rat heart. Free Radic Biol Med 2008; 45: 602-10.

71 Shyu KG, Lu MJ, Chang H, Sun HY, Wang BW, Kuan P. Carvedilol modulates the expression of hypoxia-inducible factor-1alpha and vascular endothelial growth factor in a rat model of volume-overload heart failure. J Card Fail 2005; 11: 152-9.

72 Shyu KG, Liou JY, Wang BW, Fang WJ, Chang H. Carvedilol prevents cardiac hypertrophy and overexpression of hypoxia-inducible factor1alpha and vascular endothelial growth factor in pressure-overloaded rat heart. J Biomed Sci 2005; 12: 409-20. 